\title{
Feedback and Assessment in Second Language Education: Learnings from COVID-19
}

\author{
Icy Lee $^{1}$
}

Published online: 31 October 2021

(C) De La Salle University 2021

Before COVID-19, perhaps we were pretty confident about our knowledge of feedback and assessment. Anyhow, the second language (L2) literature is replete with advice about how teachers should go about feedback and assessmentfor L2 education in general and for specific language skills such as L2 speaking and L2 writing. Whether we used certain feedback and assessment strategies or not, at least we were in control. However, the outbreak of COVID-19 threw us into disarray. Teachers found themselves unprepared and ill-equipped to cope with the huge challenges brought by the pandemic, not least the drastic shift from face-to-face to online teaching and its repercussions for feedback and assessment. Teachers had to venture outside their comfort zone to explore alternative ways of feedback and assessment.

In their call for papers for this special issue on "Feedback and assessment in second language education during the COVID-19 and beyond", guest editors Yu and Xu remarked on the key challenge brought by the pandemic: "This shift is not merely some additional use of an online technology that makes distant learning possible. It is more a matter of feedback and assessment reformulated in both form and content." Such reformulation of feedback and assessment in form and content entails not only shifts in teachers' attitudes and mindsets, but also their persistent efforts to leverage online technology to maximize student learning during these tough times.

The editors' call was answered by the research studies reported in this special issue, which add to the burgeoning

Icy Lee

icylee@cuhk.edu.hk

1 The Chinese University of Hong Kong, Shatin, Hong Kong literature on feedback and assessment in L2 education. Notably, the special issue throws light on how L2 teachers responded to the pandemic by adapting their feedback and assessment practices to cater for student needs when social isolation rendered face-to-face interaction impossibleaddressing a fundamental question raised by the editors in their call for papers: Are there any changes in teacher assessment and feedback practices? Answers to this important question can be gleaned from a number of studies, such as Mahapatra, Wu and Wang, Zhang, Yan, and Wang, and Zou, Kong, and Lee. In short, a range of online formative assessment strategies were used by teachers during the pandemic, including online quizzes, video oral presentations, online discussions, online selfassessment activities, peer assessment via WeChat groups, and the use of digital tools like Google Docs and Google Forms.

In spite of the promptness and flexibility in which teachers responded to the pandemic by modifying and enhancing their feedback and assessment practices, the challenges they faced are multifarious. Feedback is an assessment for learning strategy that enables teachers to find out how their teaching is going and how students are learning. In a face-to-face environment teachers can easily find out students' feedback from their body language and facial expressions, let alone their immediate, spontaneous verbal responses. However, in an online environment even if students turn on their web-cameras, it is much harder for teachers to figure out students' reactions, particularly when they do not show their faces during online classes. In online instruction, teachers also have a tendency to adopt the lecturing mode (particularly when most or all students have their cameras off), making dialogic feedback harder to realize. These challenges are borne out in the study by 
Yang, Mak, and Yuan, which addressed the underexplored pre-service teacher education context.

In the teacher professional, development literature, change and innovation are prominent themes (Gregersen \& MacIntyre, 2017; Hyland \& Wong, 2013). When the pandemic made teachers re-think the mode and strategies of feedback and assessment, in a real sense it was challenging them to change and to undertake innovation. Behavior changes refer to changes in teaching behaviors, such as the adoption of online technology, while cognitive changes occur at the perceptual level (Pennington, 1995)—with the latter pertaining to teachers' noticing, understanding, and making sound judgment about how best to go about feedback and assessment. To undertake innovation, teachers need to develop a growth mindset (Dweck, 2006) at the perceptual level, rather than adhere to a fixed mindset, and to stay focused on positive student learning outcome as their ultimate goal. These are critical factors that explain why some teachers, as demonstrated in some of the studies in the special issue, excelled in providing meaningful and productive formative assessment experiences for students during the pandemic. In Zou et al., for example, the teacher who was most positively engaged with formative assessment during online teaching amidst the pandemic exhibited not only behavioral change but also cognitive change, as well as a growth mindset that enabled her to embrace the challenge and persevere in her efforts despite the obstacles encountered. On the other hand, teachers with a fixed mindset, like the teacher with "disturbing" engagement with online formative assessment in the same study, was afraid of failure and unwilling to explore the use of ICT in formative assessment. Indeed, teachers' attitudes and mindsets are found to have a significant impact on the quality of student learning.

When COVID-19 began to spread rapidly across the world, inevitably attention was paid to how teachers should respond as they switched to online instruction. In fact, equally, if not more, important is how students could cope with learning in an online environment, and specifically how they could process and seek feedback as well as navigate classroom assessment in the digital space to maximize their learning. Apart from a focus on the teachers, this special issue zeroes in on the learners. In the guest editors' call for papers, another important question asked concerns the students: Are students giving each other feedback as well and much as they did in a normal classroom where peer feedback was encouraged and guided? In the feedback and assessment literature, there has been a recent surge of interest in how students engage with feedback (Han \& Hyland, 2015; Zhang, 2017) and how learner agency promotes classroom assessment (Wang \& Lee, 2021). Indeed, students could leverage the new opportunities afforded by the online environment during the pandemic to make the best of synchronous peer feedback via online discussions and interactions, as well as asynchronous peer communication in collaborative work, as demonstrated in the study by Yang et al. One advantage of feedback that takes place in the digital space is that without the face-to-face contact, some students experience a stronger sense of security and hence are more likely to share their views without much inhibition and/or concern for the face issue. Another advantage is that the online space allows students to interact with multiple partners, whereas in a face-to-face learning environment group size is a practical issue that limits the number of peers that students can interact with. In addition to student engagement with feedback, how students engage with classroombased assessment (CBA) in an online environment is a pertinent issue. The study by Yan, Zhang, and Cheng suggests that although teachers attempted to implement CBA, there was room for improvement in their practice, particularly in sharing learning goals with students and in involving them actively in the assessment process. Indeed, as pointed out by Tsao, students' self-efficacy, agency and self-regulated learning played a significant role in helping them navigate challenges arising from online learning during the pandemic.

While the articles in this special issue provide valuable learnings about feedback and assessment during COVID19, I believe that a lot of the insights generated are sound educational principles that can stand the test of time. For example, in conducting CBA (see Yan et al.), important guiding principles are the need to establish clear learning goals and assessment criteria for learners and get them to set their own goals, monitor and evaluate their learning so that they are empowered to take charge of their learning and become assessment capable (Lee, 2017). Another example is that before lectures (whether face-to-face or online) students can exercise their agency and preview teaching materials (such as assigned readings), interact with them through posing questions, and find out for themselves if their questions are addressed in the (online) lectures. Such self-feedback is conducive to learning, as shown in Yang et al.

Pandemics come and go. When COVID-19 is over, life will get back to normal. But who knows? Any time we may be hit by another pandemic that requires us to respond promptly by garnering all our resources to provide the best possible educational experiences for our students. What lies beyond COVID-19 is in the balance. However, with the insights gained from this special issue, we would be able to move forward with a greater sense of certainty of what we can do to enhance feedback and assessment should another unprecedented challenge befall us. 


\section{References}

Dweck, C. S. (2006). Mindset: The new psychology of success. Random Hose.

Gregersen, T. S., \& MacIntyre, P. D. (Eds.). (2017). Innovative practices in language teacher education: Spanning the spectrum from intra-to inter-personal professional development. Springer.

Han, Y., \& Hyland, F. (2015). Exploring learner engagement with written corrective feedback in a Chinese tertiary EFL classroom. Journal of Second Language Writing, 30, 31-44. https://doi.org/10.1016/j.jslw.2015.08.002

Hyland, K., \& Wong, L. (2013). Innovation and change in English language education. Routledge.
Lee, I. (2017). Classroom assessment and feedback in L2 school contexts. Springer.

Pennington, M. (1995). The teacher change cycle. TESOL Quarterly, 29(4), 705-731. https://doi.org/10.2307/3588171

Wang, L., \& Lee, I. (2021). L2 learners' agentic engagement in an assessment as learning-focused writing classroom. Assessing Writing, 50, 100571. https://doi.org/10.1016/j.asw.2021.100571

Zhang, Z. (2017). Student engagement with computer-generated feedback: A case study. ELT Journal, 71(3), 317-328. https://doi.org/10.1093/elt/ccw089

Publisher's Note Springer Nature remains neutral with regard to jurisdictional claims in published maps and institutional affiliations. 